The University of San Francisco

USF Scholarship: a digital repository @ Gleeson Library |

Geschke Center

Business Analytics and Information Systems

School of Management

7-17-2013

\title{
Using Work System Theory to Link Managerial and Technical Perspectives on BPM
}

Steven Alter

University of San Francisco, alter@usfca.edu

Follow this and additional works at: http://repository.usfca.edu/at

Part of the Business Commons

\section{Recommended Citation}

Alter, S.. 2013, "Using Work System Theory to Link Managerial and Technical Perspectives on BPM," Complete version of an abbreviated paper published as pp. 222-227 in Proceedings of the IEEEInternational Conference on Business Informatics, Vienna, Austria, July 15-18, 2013

This Article is brought to you for free and open access by the School of Management at USF Scholarship: a digital repository @ Gleeson Library | Geschke Center. It has been accepted for inclusion in Business Analytics and Information Systems by an authorized administrator of USF Scholarship: a digital repository @ Gleeson Library | Geschke Center. For more information, please contact repository@usfca.edu. 


\title{
Using Work System Theory to Link Managerial and Technical Perspectives on BPM
}

\author{
Steven Alter \\ School of Management \\ University of San Francisco \\ San Francisco, USA \\ alter@usfca.edu
}

\begin{abstract}
Work system theory (WST) provides a bridge between managerial and technical perspectives on BPM that often seem distant from each other. In combination, the work system framework, underlying work system metamodel, and the work system life cycle model provide a number of bridges between those perspectives. In relation to managerial BPM, the work system framework treats "business process" as one of nine elements in a basic understanding of a work system. The others are participants, information, technology, products/services, customers, environment, infrastructure, and strategies. The underlying metamodel outlines a precise structure for analysis and design of work systems and for links to technical aspects of BPM. It provides details that are omitted from the work system framework, which has proven useful for initial high level summaries but is not granular enough to support detailed design and documentation. The work system life cycle model combines planned and unplanned (emergent) change through which work systems evolve. This paper explains where WST fits in the general realm of BPM-related topics and how WST might help in developing BPM further. It also identifies challenges and next steps related to using WST to expand the scope of BPM.
\end{abstract}

Keywords-Business process management, work system, work system framework, work system metamodel, work system life cycle model

\section{THE GAP BETWEEN MANAGERIAL BPM AND TECHNICAL BPM}

The vast gap between managerial and technical perspectives on business process management (BPM) reveals a significant challenge for BPM practice and research. Consider, for example, differences in scope and emphasis between typical managerial BPM topics (organizational change, process organizations, TQM, e.g., [1], [2], [3]), and typical technical BPM topics (detailed modeling, programming techniques, high degree of abstraction, automated process control or discovery, e.g., [4],[5], [6], [7]). Other sources try to span business and technical views of BPM (e.g., [8]. [9], [10]).

The importance of the managerial/technical gap is reflected in the website of Gartner, a leading IT consulting firm [11], which says that BPM "is a management discipline that treats business processes as assets that directly contribute to enterprise performance" ... "The most critical disciplines for BPM success are related to nontechnical issues, such as changing people's attitudes and assumptions based on building a new frame of reference or perspective." Such difficulties are mentioned in a 2011 Gartner consulting report [10], which says "BPM as a discipline has moved further into the Trough of Disillusionment [Gartner's term for a period of disappointment after a period of increasing hype], reflecting the reality of making BPM work beyond pilot projects or initiatives. The challenge for many is in institutionalizing BPM into the organization and realizing the transformational change and business benefits anticipated by their investments." An approach for addressing this challenge requires actionable and readily understandable linkages between managerial and technical aspects of BPM.

This paper defines BPM in a way that emphasizes management concerns while also encompassing BPM-related software and analytical rigor. Following [12], BPM is defined as "supporting business processes using methods, techniques and software to design, enact, control and analyze operational processes involving humans, organizations, applications, documents and other sources of information."

The divergent nature of managerial and technical perspectives on BPM derives from their origins. The managerial side of BPM comes from organizational behavior and operations management, focusing on behavior, strategies, and operational techniques, but often glossing over the way that organizations operate through reasonably well defined work systems. As it first developed, the technical side of BPM appeared to assume that business processes will be performed as designed. Subsequent research in process-aware information systems (e.g., [4], [13]) and process mining and adaptive case management (e.g., [14]) retains a rigorous analytic focus as it moves toward recognizing contingencies, inconsistencies, and even non-compliance that typical managers face every day when managing business processes. Interestingly, managerial BPM that emphasizes TQM and Six Sigma sometimes struggles with the same issues by treating inconsistencies and non-conformance as defects rather than realities of work life.

Progress in linking managerial and technical aspects of BPM could provide benefits in many areas. From the managerial side, it could help managers and business professionals visualize business process issues that are not reflected fully in existing tools and methods for process modeling. Going beyond idealized business process logic, those issues involve characteristics of participants, information, technology, and products/services produced for a work system's customers, concerns of customers, and the relevant 
environment, infrastructure, and strategies. From the technical side it could lead to better BPM software, documentation, and analysis methods that in turn could make the management of business processes more effective. In addition, it could lead to better communication between managers and technical experts.

This paper shows how results of research about integrating sociotechnical and technical views of systems in organizations provides potential links between technical and managerial aspects of BPM. That research generated basic ideas in work system theory (WST), which covers the operation of a work system within its context and the processes through which it evolves over time. WST is the basis of various versions of the work system method [15], a systems analysis method in which the "as-is" and "to-be" systems are sociotechnical work systems by default rather than technical artifacts. The research also generated extensions of WST, including work system principles, work system design spaces, a metamodel for describing a work system in greater detail than the initial framework, a theory of workarounds, a theory of system interactions based on work systems, and other extensions [16].

This paper approaches BPM from a unique starting point that is between typical management perspectives and typical technical perspectives, as illustrated in Fig. 1. First it summarizes the two central frameworks in WST: 1) the work system framework, which identifies nine elements of a basic understanding of an operational work system, and 2) the work system life cycle model, which explains how work systems evolve over time. Next it summarizes an extension of WST in the form of a metamodel that provides a more detailed view of the topics covered by the work system framework. It shows that WST provides valuable linkages between managerial and technical views of BPM, thereby addressing the practical problem of translating between technical and non-technical views of phenomena that are often understood and discussed within disconnected intellectual silos whose separation inhibits mutual understanding. Other aspects of WST and its extensions that are relevant are mentioned briefly to indicate additional directions in which WST might contribute.

\section{BASIC COMPONENTS OF WORK SYSTEM THEORY}

The work system framework (Fig. 2), work system life cycle model (Fig. 3) and work system metamodel (Fig. 4) are products of a long term research project directed at creating a systems analysis method that business professionals can use for their own understanding and that could support communication between business and IT professionals. The more recent metamodel extended previous research and fits with a largely European tradition of creating constructs and models that are rigorous and are relevant to many situations [17].

Work systems are systems in which human participants and/or machines perform processes and activities using information, technology, and other resources to produce products/services for internal and/or external customers. By that definition, most IT-reliant systems within or across organizations are work systems, including information systems, service systems, ecommerce web sites, and even entire supply chains (that cross multiple organizations). By default, work systems are assumed to be systems in which human participants use technology when executing processes and activities. "Human participants and/or machines" indicates that the definition also covers totally automated work systems that perform work autonomously (e.g., computer programs and automated agents). Even when a work system has human participants, decomposition during analysis and design often reveals totally automated subsystems that are work systems.

Almost all value chain and support systems are IT-reliant work systems. Over 700 such systems have been analyzed by employed MBA or Executive MBA students at universities in the United States, China, and Vietnam. These employed students applied work system analysis templates to produce management briefings and improvement recommendations for work systems in their own organizations. They summarized the "as is" work system, identified problems and opportunities, summarized a proposed "to be" work system, and clarified why proposed changes would improve performance. These were preliminary analyses for exploring and understanding issues, rather than precise, highly detailed specifications of an "as is"

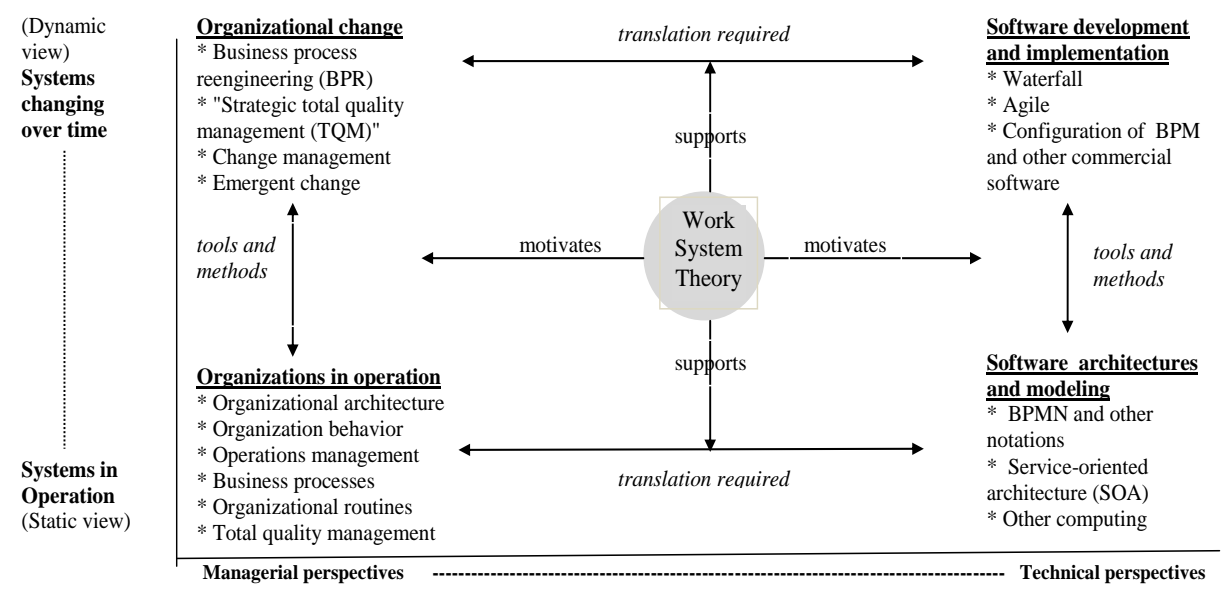

Fig. 1. Positioning the work system theory in relation to BPM topics 


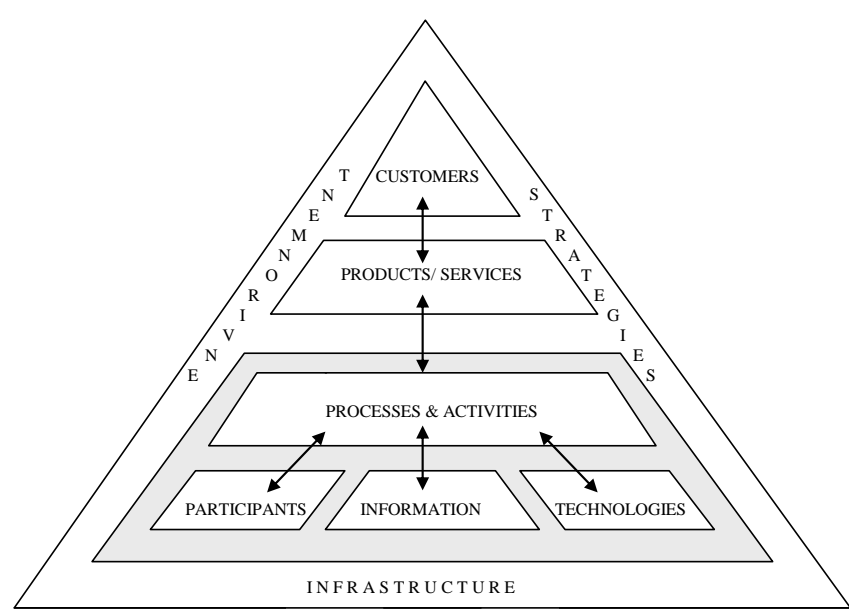

Fig. 2. Work system framework

or "to be" work system. ([18], [19]). The following are typical examples of the work systems that were analyzed:

- Renewing insurance policies

- Collecting and reporting sales data for a wholesaler

- Timekeeping for technicians for a public utility

- Receiving materials at a large warehouse

- Performing pre-employment background checks

- Planning for outages in key real time information systems

- Finding and serving a consulting firm's clients

- Invoicing for construction work

- Approving real estate loan applications

- Planning and dispatching trucking services

- Scheduling and tracking health service appointments

- Operating an engineering call center

Work system framework. Fig. 2 identifies nine elements of a basic understanding of a work system at a particular time, including who the customers are, what products and services are produced, what are the major processes and activities, and so on. These elements are defined in [15], [20], [16]. Fig. 2 says that work systems exist to produce products and services for customers. The arrows say that the elements of a work system should be in alignment. In many situations, customers are also participants, e.g., medical services. The environment, infrastructure, and strategies are not part of the work system but are part of an understanding of a work system.

Work system life cycle model. Fig. 3 expresses a dynamic view of how work systems change over time through iterations of planned and emergent (unplanned) change. These iterations proceed through four phases: operation and maintenance of an existing work system (including incremental adaptations and workarounds), initiation of projects, development or acquisition of resources such as software, procedures, and training material, and implementation in the organization, in combination leading to a new version of the work system.

Work system metamodel. The work system framework is useful for summarizing a work system and achieving mutual

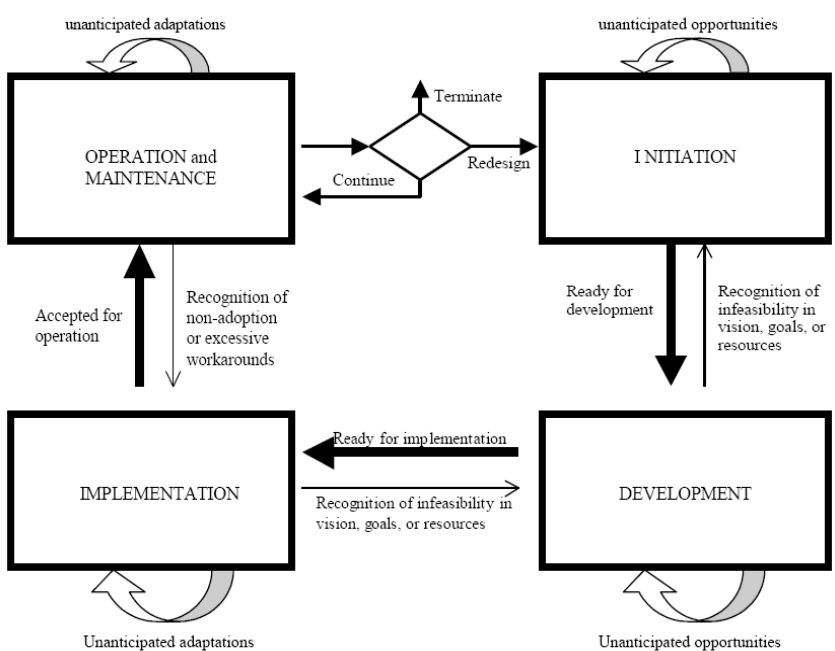

Fig. 3. Work system life cycle model

understanding of the scope and nature of a work system, but is less effective as a tool for detailed analysis. Ideally, a framework for detailed analysis should be more precise about concepts and important relationships between concepts. Ideally, a more rigorous framework would support deeper analysis without requiring terminology (e.g., objects and classes) that is impenetrable to most business professionals.

The work system metamodel [21], [22] builds upon the work system framework by making its concepts clearer, more rigorous, and more useful in work system documentation and software development. It creates a bridge between a summary level description of a work system and more detailed models as the work system is decomposed into subsystems during analysis and design. It does that without requiring the precision, terminology, and notation of BPMN or of rigorous software specifications. When used in conjunction with a second layer identifying common characteristics, metrics, and principles for specific elements, it can support traceability between summary level analysis by business professionals and more detailed analysis and documentation by IT specialists.

Each element of the work system framework is represented in the metamodel, as shown by shading in Fig. 4, although most are re-interpreted in a more detailed way. For example, information becomes informational entity, technology is divided into tools and automated agents, activities are performed by three types of actors, and so on. Whereas the work system framework does not include the term user, the metamodel includes "uses" as a relationship between a participant and a tool (which is one of two guises of technology). Representation decisions in the metamodel try to maximize understandability while revealing potential omissions from an analysis or design process.

Fig. 4 hides a large number of important attributes such as goals, characteristics, metrics, and principles that apply to specific elements and relationships in the metamodel. Analysts using the metamodel would consider and apply the hidden attributes while defining the problem or opportunity, evaluating the "as is" work system, and justifying proposed improvements that would appear in the "to be" work system. 


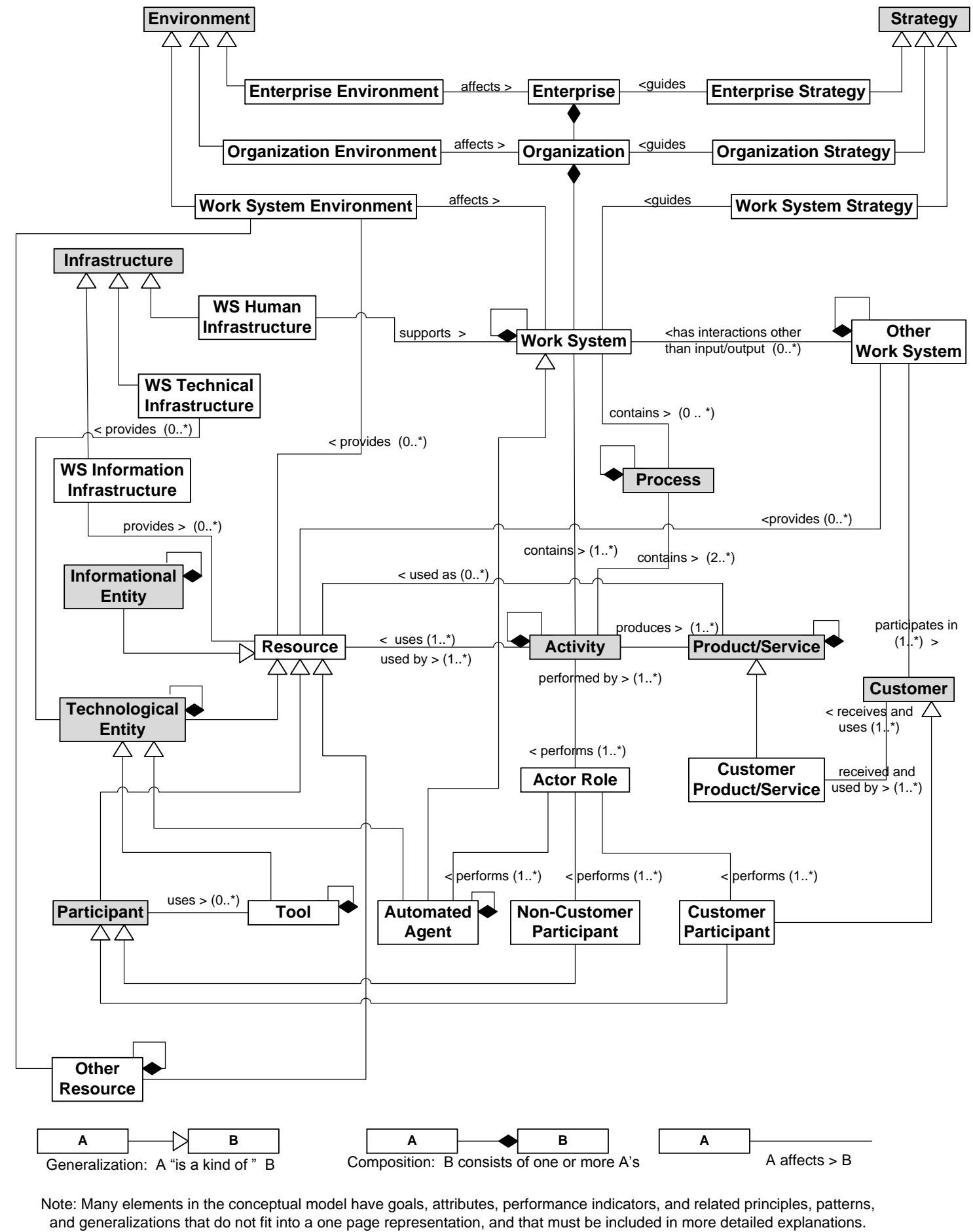

Fig. 4. Metamodel for integrated analysis and design of sociotechnical and technical systems

\section{WHERE WORK SYSTEM THEORY FITS}

Fig. 1 positioned WST centrally in a rectangle whose horizontal dimension goes from managerial to technical and whose vertical dimension goes from systems in operation (static view) to systems changing over time (dynamic view).
- The managerial static view represents a system that maintains its form and integrity as it operates even though it may change slightly through adaptations and workarounds during the time period of interest.

- The technical static view is basically the detailed documentation of how the work system is supposed to operate. 
- Both the managerial and technical dynamic views are about how the system changes over time. The managerial side is about planned and emergent change. The technical side is about software development and implementation.

The central position of WST in Fig. 1 is a place from which it can help in bridging differences between managerial and technical perspectives. Fig. 1 says that WST can support required translations between the managerial and technical, both in relation to systems in operation and systems changing over time. In addition, WST potentially motivates tools and methods for creating or improving systems in organizations.

Unit of analysis. Potential roles of WST in relation to managerial and technical BPM are based on its use of the work system as the unit of analysis. As stated earlier, a work system is a system in which human participants and/or machines perform processes and activities using information, technology, and other resources to produce products/services for internal and/or external customers. The work system framework (Fig. 2) identifies nine elements of a basic understanding of a work system. Managerial BPM (the left side of Fig. 1) must pay attention to those elements because each of them may be a source of opportunity, difficulty, or failure. The unit of analysis in technical BPM (rigorous specifications and automated control of a business process) is clearly incomplete as a unit of analysis for managerial BPM. Translation and coordination between managerial and technical BPM should recognize that the benefits of technical BPM are realized within the broader scope of work system operation and improvement.

Span of concerns. The managerial view of business process, information, and other relevant topics recognizes that idealized business processes may not be followed due to temporary obstacles, workarounds, adaptations, confusion, and even non-compliance by participants. It recognizes that relevant information includes much more than computerized information that might be identified or implied in applications of BPM tools. It needs to address all of the following issues:

- whether the design of the work describes efficient and effective work patterns (process specification),

- whether the work is done correctly (process monitoring and process controls),

- whether the results meet performance goals (metrics),

- whether people doing the work are adequately skilled and motivated (participants),

- whether obstacles and contingencies are getting in the way (situated realities, not just idealizations),

- whether the work is producing products/services that internal and/or external customers need and want.

Technical BPM has a narrower range of primary concerns. In addition, it tends to portray business processes in a more rigorous manner than is needed by many managers in many situations. Even if they want to take advantage of BPM capabilities, many managers may not understand how to apply BPM tools that seem to belong in the realm of technical experts.

\section{HOW WORK SYSTEM THEORY Might HeLP}

As noted in Gartner's 2011 statement [10], the gap between managerial and technical BPM impedes mutual understanding and real world adoption, making it challenging to move from pilot BPM implementations to genuine benefits. For typical managers, the management of business processes involves management activities such as designing, implementing, supervising and improving reasonably well defined processes that routinely encounter exceptions and contingencies related to human, social, and external factors. For technical experts, BPM produces precise process specifications that guide or control process sequence and logic.

Arrows in Fig. 1 identify ways in which WST might help in creating linkages between managerial and technical BPM and in supporting both perspectives individually. The arrows say that WST might support required translations between managerial and technical perspectives related to systems in operation and related to systems changing over time. Within both managerial and technical perspectives, WST might motivate new tools and methods. This section identifies routes for achieving those benefits, starting with the four corners of Fig. 1 and proceeding to linkages and new tools and methods.

\section{A. How WST Might Support Separate Perspectives}

1) Managerial perspective on systems in operation. "Work system" is a natural unit of analysis for managerial BPM because achieving business results requires attention to all nine elements of the work system framework. In relation to managerial BPM this unit of analysis is more focused and operational than broad brush ideas such as process-as-strategy and change management. From the other direction, any attempt to manage a business process without careful attention to the attributes of human participants, information, technology, and other work system elements would likely encounter difficulties because business process performance depends on much more than the idealized sequence and logic of the business process.

2) Managerial perspective on systems changing over time. Similarly, the work system life cycle model is an appropriate basis for a managerial BPM perspective on how systems change over time. This model does not assume that an announced change in the sequence or other details of a business process automatically translates into a corresponding organizational change. Instead, it recognizes that planned change involves a project with initiation, development, and implementation phases. More important, the project is a work system project, not just a BPM project or IT project. The goal is to improve work system performance, not just to install a technology that controls processes within the work system. Furthermore, the model recognizes unplanned adaptations and workarounds that occur during operation and maintenance and 
during each of the project phases. Those unplanned changes often provide insights that lead to subsequent improvements.

3) Technical perspective on systems in operation. The work system metamodel reinterprets the elements of the work system framework in a more rigorous form that is stylistically and conceptually closer to precise specifications of business process sequence and logic. The metamodel can be used to categorize concepts within any version of BPM and to identify work system elements or concepts that are ignored or viewed as unproblematic. For example, the metamodel contains the element participant whose attributes include characteristics related to skills, knowledge, training, interest, incentives, and so on. Inspection of any particular version of technical BPM can determine whether it includes concepts that are synonyms of participant and related attributes. The same can be done for other elements and concepts such as informational entity, which includes transaction data, plans, informal commitments, and other types of computerized or non-computerized information, and technological entity, which includes tools that are used by participants and automated agents that operate autonomously after being launched by participants or other automated agents. Thus, WST can help in clarifying what is included and what is excluded from a specific technical perspective on BPM. In addition, it may raise issues about why some entity types are or are not included.

4) Technical perspective on systems changing over time. The work system life cycle model says that a BPM project is part of a larger project devoted to improving a work system's performance using BPM software in conjunction with other changes that may or may not involve BPM. The project will not be successful until the work system changes as a whole. Just installing BPM software will not solve the problem.

\section{B. How WST Might Support Linkages between BPM Perspectives}

1) Linking managerial and technical perspectives on systems in operation. Over 700 employed MBA students have used WST-based work system analysis templates to perform preliminary analyses of work systems in their organizations and to produce recommendations for improvements. [18], [19]. The demonstrated practicality of this approach, at least for producing preliminary analyses, shows that WST provides a frame of reference that business professionals can use by themselves. If they can do that, they can certainly use it when collaborating with BPM and IT professionals, thereby addressing a difficult translation problem between two very different perspectives. From the other direction, using WST as a communication tool would require BPM professionals to be fluent in an additional, less rigorous modeling method. The challenge of learning that method would minimal, however, since many MBA students have learned to apply the core of WST in only several hours of instruction and subsequent work.

The linkage between the two perspectives would start by using an appropriate variation on existing work system templates to establish a mutual understanding of the work system containing the business process of interest. The remainder of the analysis would go into more detail. This could be done using tools mentioned below that are based on the work system metamodel. The direct result of using those tools would not be a complete specification in BPMN or a similar notation, but would be a significant step from a managerial overview of a work system toward a detailed specification of the business process in the "as-is" or "to-be" work system.

2) Linking managerial and technical perspectives on systems changing over time. The work system life cycle model was designed as an intermediate representation combining selected ideas from organizational change and from IT-related life cycle models (e.g., the SDLC) that are called life cycle models but actually are project models. The work system life cycle model recognizes that work systems evolve through iterations that incorporate planned and unplanned change. At all times both types of change are fundamentally about improving a work system rather than creating, installing, or using a technical artifact such as BPM software.

Using the work system life cycle model encourages managers and technical experts to look at the same unit of analysis, i.e., the process of creating improvements in a particular work system. Clarity about the unit of analysis helps in avoiding confusion that sometimes occurs when technical experts think of projects as BPM or IT projects while business professionals focus on performance improvement and business results. That clarity also helps in communicating about the distinct challenges of the technical aspects of the project. It becomes increasingly clear that software projects do not create organizational change. The goal is to produce better performance by improving work systems, not just to install BPM software and produce rigorous process models.

\section{How WST Might Motivate New BPM Tools}

1) New tools for a managerial perspective. Various versions of work system analysis templates have been developed. A basic tool that they share is a "work system snapshot," [15], [16], a one page summary of a work system in terms of the six central elements of the work system framework: customers, products/services, processes and activities, participants, information, and technologies. The requirement of not exceeding one page helps focus attention on the scope of the system and prevents getting overwhelmed at the outset in details that subsequent analysis will reveal. A set of internal consistency guidelines encourage a reasonable level of rigor without being burdensome. The result is a summary of an as-is or to-be work system that can be inspected and discussed easily and that serves as a reference point for the rest of the analysis. If the analysis concludes that software should be purchased, referring to the work system snapshot raises questions about which of its six elements will be affected and in what way. If technology is the only element that will change or will perform better, it is unlikely that introducing BPM software will make much difference.

2) New tools for a technical perspective. BPM research has developed workflow software, BPMN, and other BPM 
tools and software products. Relationships in the metamodel could lead to analysis and design tools that may be missing from some versions of BPM. For example, tables based on links in the metamodel may lead directly to simple tabular tools. Such tools devote one column to a specific element in the metamodel (e.g., activity, participant, informational entity, or other resource within the work system) and devote another column or several columns to directly related elements. Typical tables might include participants in all activities at a particular level of decomposition, informational entities used by each activity, or a set of characteristics or metrics related to activities, informational entities, or participants. It is possible to develop hierarchy-oriented tools that extend those tables across levels of decomposition.

In a more general sense, the metamodel provides an organizing structure for generating a series of tools based on a broad view of systems in organizations. Tools within technical BPM basically view the business process as the system. The approach for generating new tools is to start with the metamodel, including hidden attributes of various entity types, and to look for ways in which that information is a step toward the existing or proposed BPM tools. At that level the gaps will be much narrower than gaps between managerial and technical BPM in general. These new gaps might be addressed through algorithms or through guidelines that cannot be automated but are clear enough to help BPM experts perform the translations quickly and efficiently.

\section{CHALLENGES AND STEPS TOWARD NEW TOPICS}

While much additional research is required to develop and test non-trivial instantiations of links between managerial and technical BPM, this paper contributes to BPM research by suggesting a direction that has not been attempted. That direction involves using WST as a starting point and consciously moving toward topics in technical BPM, both from the viewpoint of managers who want to improve work systems and from the viewpoint of BPM experts who see value in expanding the scope of BPM beyond ongoing research areas such as process mining, process discovery, and treatment of exceptions. For the managerial side, just using frameworks and templates for thinking about business processes in work system terms provides a richer frame of reference that highlights many issues that a narrower BPM approach might not reveal. For the technical side, the combination of the work system framework, the metamodel, and the work system life cycle model provides an internally consistent lens for seeing the current scope of technical BPM and for thinking about potentially beneficial directions for research.

This final section focuses on specific topics related to WST that provide opportunities for further development of BPM.

\section{A. Alternative design spaces.}

A work system design space is a category of things that might change or whose problematic nature might impel change in relation to any work system element, any subsystem of a work system, or the work system as a whole.[23] To date, seven such design spaces have been described, each of which might indicate a possible direction for extension of BPM.

- Adherence to work system principles. BPM should include a set of operational principles that can be used for evaluating the structure and potential performance of business processes. Lack of adherence to any principle might be an indication of faulty design. Extending a previous set of sociotechnical principles [24], a set of 24 work system principles mentioned in [16] and previous articles might provide a point of departure, e.g., by serving as an initial set of principles that might be developed further to suit the needs of BPM efforts.

- Generic types of changes, e.g., adding, combining, or eliminating steps in a process, upgrading hardware and software, changing the nature of customer relationships or the customer experience.

- Big picture choices represented as multiple design dimensions, e.g., from simple to complex, from unstructured to totally structured, from loosely coupled to tightly coupled, and from manual to automated. The related questions include: How structured should this process be? How complex should it be? How integrated should the work system be? What is the right amount of variety in the work? and so on.

- Alternative locations of information and knowledge. This is relevant because information and knowledge can reside within any of the work system elements, e.g., built into the process or into the technology or in the heads of the participants.

- Common risks and obstacles. Good design should take into account common risks and obstacles that are often associated with each element of the work system framework and with the work system as a whole.

- Direct and indirect interactions with other work systems. Every work system is related to other work systems and experiences direct and/or indirect interactions with other work systems. Both designed interactions and anticipation of unintended interactions should be part of system design (to the extent possible).

- Alternatives for facilitating value for customers. Since the purpose of work systems (and hence their business processes) is to facilitate value for customers [26], BPM should support consideration of alternative approaches for facilitating value.

\section{B. Challenges related to process regularity and repeatability.}

$\mathrm{BPM}$ research is moving toward handling greater flexibility in process operation. Comparison of WST and its extensions with any particular version of BPM could help in clarifying assumptions about the regularity and repeatability of process steps. Possible assumptions include the following: 
- Expectation of total conformance to unambiguous process specifications.

- Expectation of intention to conform to unambiguous process specifications, with variability of outcomes due to errors, exceptions, and contingencies.

- Expectation of variability of process execution due to a combination of errors, exceptions, contingencies, and intentional non-conformance to process specifications. Such non-conformance might result from rework, exceptions, and contingencies plus the impact of personal or group preferences and goals.

More broadly, any particular version of BPM should be clear about whether and how it treats each of each of the following issues that arise in WST:

- conformance or non-conformance to documented business processes and to organizational routines that have emerged over time [26] (i.e., the process-inpractice may deviate from the process-as-designed or from the process-as-generally-practiced).

- treatment of unanticipated exceptions and contingencies

- variability in the skills and motivation of participants

- accuracy or inaccuracy of information used and created by business processes

- reliability or unreliability of technology

- satisfaction or dissatisfaction of internal or external customers regarding products and services produced.

- support, obstacles, and uncertainties related to the surrounding environment and the shared infrastructure that business processes rely upon.

\section{Making a business case for BPM}

Cost/benefit analysis related to IT innovations in general and BPM software in particular is often questionable because the benefits are difficult to articulate beyond the level of slogans (e.g., better control, better decisions, happier customers). In combination, the work system framework, work system life cycle model, and metamodel might provide the level of specificity that reveals clearer descriptions and quantification of business performance benefits. Within a work system rationale, the benefits and costs are related to moving from the "as is" work system to the "to be" work system. This involves much more than installing new BPM capabilities that seem potentially helpful. Thus, applying WST to express the justification at the work system level could provide a more realistic view of what would change and of the difficulties in accomplishing those changes.

\section{REFERENCES}

[1] T. H. Davenport, Process innovation: reengineering work through information technology. Cambridge, Harvard Business Press, 1993.

[2] M. Hammer and J. Champy, Reengineering the corporation: a manifesto for business revolution. New York: Harper Business, 1993.
[3] P. G. W. Keen, The process edge: creating value where it counts, Cambridge: Harvard Business Press, 1997.

[4] M. Dumas W. M,. van der Aalst,and A.H. ter Hofstede, Process aware information systems: bridging people and software through process technology. Hoboken: Wiley, 2005.

[5] J. Recker, M. Rosemann, M. Indulska, and P. Green, "Business process modeling- a comparative analysis", Journal of the Association for Information Systems (10)4, 2009, pp. 333-363.

[6] J, Recker M. Indulska. M, Rosemann and P. Green, "The ontological deficiencies of process modeling in practice," European Journal of Information Systems, 19(5), 2010, pp. 501-525.

[7] W. M. P. van der Aalst, Process mining: discovery, conformance and enhancement of business processes, Berlin: Springer, 2011.

[8] R. K. Ko, "A computer scientist's introductory guide to business process management (BPM)," Crossroads, 15(4), 2009, pp. 11-18.

[9] J. vom Brocke and M. Rosemann (eds.) Handbook on Business Process Management 1, Berlin: Springer, 2010

[10] J. Dixon and T. Jones "Hype cycle for business process management", Gartner Report G00214214, 2011.

[11] Gartner. "Business Process Management (BPM)," http://www.gartner.com/it-glossary/business-process-management-bpm/, 2013.

[12] W. van der Aalst, , A. ter Hofstede, and M. Weske, "Business process management: A survey," in W. van der Aalst, , A. ter Hofstede, and M. Weske, eds., International Conference on Business Process Management (BPM 2003), volume 2678 of Lecture Notes in Computer Science, Berlin: Springer, , 2003. pp. 1-12.

[13] M. Reichert and B. Weber, Enabling Flexibility in Process-Aware Information Systems: Challenges, Methods, Technologies. BerlinHeidelberg: Springer, 2012.

[14] W. M. P. van der Aalst, "Process mining manifesto," BPM 2011 Workshops Proceedings, Springer-Verlag, Campus des Cézeaux, Clermont-Ferrand, 2012, pp. 169-194.

[15] S. Alter, The Work System Method: Connecting People, Processes, and IT for Business Results, Larkspur: Work System Press, 2006

[16] S. Alter, Work System Theory: Overview of Core Concepts, Extensions, and Challenges for the Future," Journal of the Association for Information Systems, 2013, in press.

[17] R. Winter, "Design science research in Europe," European Journal of Information Systems, (17)5, 2008, pp. 470-475

[18] D. Truex, S. Alter, and C. Long, "Systems analysis for everyone else: empowering business professionals through a systems analysis method that fits their needs," Proceedings of 18th European Conference on Information Systems, Pretoria, South Africa, 2010.

[19] D. Truex, N. Lakew, S. Alter, and S. Sarkar, "Extending a systems analysis method for business professionals," European Design Science Symposium, Leixlip, Ireland, 2011.

[20] S. Alter, "Defining information systems as work systems: implications for the IS field," European Journal of Information Systems (17)5, 2008, pp. 448-469.

[21] S. Alter, "Bridging the chasm between sociotechnical and technical views of systems in organizations," Proceedings of ICIS 2010, 31st International Conference on Information Systems, 2010.

[22] S. Alter, "Metamodel for Service Analysis and Design Based on an Operational View of Service and Service Systems," Service Science, 4(3), 2012, pp. 218-235.

[23] S. Alter, "Work systems as the core of the design space for organisational design and engineering," International Journal of Organisational Design and Engineering, (1)1, 2010, pp. 5-28.

[24] A. Cherns, "Principles of socio-technical design," Human Relations, (2) 9, 1976, pp. 783-792.

[25] C. Grönroos, "Value creation in service logic: A critical analysis," Marketing Theory, (11)3, 2011, pp. 279-301.

[26] M. S. Feldman, and B. T. Pentland, "Re-theorizing organizational routines as a source of flexibility and change," Administrative Science Quarterly, (48), 2003, pp. 94-118. 